\title{
СПЕКТР ПРОТИВОВИРУСНОГО ДЕЙСТВИЯ ВОДОРАСТВОРИМЫХ ПРОИЗВОДНЫХ ФУЛЛЕРЕНА
}

\author{
Е.О. Синегубова', А.С. Волобуева', О.А. Краевая², А.В. Жиленков²,
} П.А. Трошин ${ }^{2}$, В.В. Зарубаев ${ }^{1}$

\begin{abstract}
1Лаборатория экспериментальной вирусологии, ФБУН НИИ эпидемиологии и микробиологии имени Пастера, 197101, Россия, Санкт-Петербург, улица Мира, 14. 2Лаборатория функциональных материалов для электроники и медицины, Институт проблем химической физики РАН, 142432, Россия, Черноголовка, пр. ак. Семенова, 1
\end{abstract}

DOI: 10.19163/MedChemRussia2021-2021-320

E-mail:sinek489@gmail.com

В настоящее время биологические свойства фуллеренов и их функциональных производных активно изучаются с целью создания на их основе новых лекарственных средств, но спектр их противовирусной активности охарактеризован не полностью.

По результатам скрининговых тестов более 160 производных фуллеренов, отличавшихся структурой солюбилизирующихаддендов, были определены 5 соединений-лидеров. Исследованиеспектра противовирусной активности соединений-лидеров проводили на пермиссивных культурах клеток (MDCK, Vero) с использованием вирусов гриппа A/PuertoRico/8/34 (H1N1), A/Aichi/2/68 (H3N2), A/ mallard/Pennsylvania/1984 (H5N2), A/California/07/09 (H1N1)pdm09, А/Владивосток/2/09 (H1N1), A/Anhui/1/2013 (H7N9), вируса Коксаки B3, вируса герпеса 1 типа и аденовируса человека 5 типа. Вирусы культивировали в течение 72-120 ч в присутствии изучаемых соединений в диапазоне концентраций 4-300 мкг/ мл, после чего определяли инфекционность вирусного потомства и оценивали цитотоксичность исследуемых веществ при помощи титрования вируса в клетках, реакции гемагглютинации и МТТ-теста. На основании полученных данных рассчитывали 50 \% цитотоксическую концентрацию $\left(\mathrm{CC}_{50}\right), 50$ \% ингибирующую концентрацию $\left(\mathrm{IC}_{50}\right)$ и индекс селективности $(\mathrm{SI})$ - отношение $\mathrm{CC}_{50}$ к IC $\mathrm{I}_{50}$ для каждого вещества.

Все соединения-лидеры имели выраженный ингибирующий эффект в отношении вируса герпеса 1 типа и различных подтипов вируса гриппа. Но они не проявляли ингибирующей активности в отношении вирусов, лишенных суперкапсида, таких как аденовирус 5 типа и вирус Коксаки В3. Максимальную активность в отношении вируса герпеса $\left(\mathrm{CC}_{50}>220 \mathrm{nmol}, \mathrm{IC}_{50}=1,8 \mathrm{nmol}, \mathrm{SI}=122\right)$ проявляло производное фуллерена с присоединенными остатками калиевой соли 3-аминопропановой кислоты. Полученные данные позволяют предположить, что белки суперкапсида вирусов представляют собой мишень для действия фуллеренсодержащих соединений, и создают перспективу для дальнейшего изучения противовирусной активности водорастворимых производных фуллерена.

Результаты получены при поддержке Российского научного фонда (проект № 19-13-00411). 